\title{
Application of Principal Component Analysis and Response Surface Methodology in the Process of Steel Wire Tempering
}

\author{
Cristie Diego Pimenta ${ }^{1}$, Messias Borges Silva ${ }^{2}$, Rose Lima de Morais Campos ${ }^{3}, \&$ Fabrício Maciel Gomes ${ }^{4}$ \\ ${ }^{1}$ Department of Business, ITES College, Sao Paulo, Brazil \\ ${ }^{2}$ Department of Production, University of Guaratingueta (Feg-Unesp), Sao Paulo, Brazil \\ ${ }^{3}$ Department of Business, ITES College, Sao Paulo, Brazil \\ ${ }^{4}$ Department of Production, University of São Paulo (USP), Sao Paulo, Brazil \\ Correspondence: Cristie Diego Pimenta, Department of Business, ITES College, 3575 Av. D. Pedro I., Jardim Eulália - \\ Taubaté/SP, Brazil.
}

Received: October 14, 2019 Accepted: December 18, 2019 Online Published: December 23, 2019

doi:10.5539/ijsp.v9n1p9 URL: https://doi.org/10.5539/ijsp.v9n1p9

\begin{abstract}
The purpose of this work was the creation of a statistical modeling capable of replacing the process used to set up of the ovens of the quenching and tempering who is traditionally accomplished through adjustments made based on the results of mechanical properties tested in laboratory and required in customer specifications. This study seeks to understand the influence of input variables (factors) on the tensile strength limit, in SAE 9254 draw steel wires, with diameters 2.00 $\mathrm{mm}$ and $6.50 \mathrm{~mm}$, used in the manufacture of valve springs and clutch springs for automobiles. The process input variables were investigated: steel wire diameter, processing speed, temper temperature and liquid polymer concentration (which is the tempering medium). Methodologies were used where design of experiments, multiple regression and quadratic regression, principal components analysis (multivariate statistical) and response surface methodology. Results revealed which variables are significant in the process. Also models obtained were validated using appropriate statistical methods. If this study is used, it can provide the automation of this process. It's important to point out that it could impact the increase in productivity and quality of product.
\end{abstract}

Keywords: quenching, design of experiments, principal components analysis, response surface methodology

\section{Introduction}

This research, statistical methods were used to assist in the development of a statistical modeling to come to replace the traditional way (trial and error) as adjustment of the input variables of the heat treatment oven. In this specific case, the initial setting was performed by means of tests of mechanical property (tensile strength limit) in a sample pilot. After going through all steps of a heat treatment, also will be forwarded to the physical laboratory analysis.

This implies considerably operating routine analysis and waiting time, reducing the productivity of the process due to low income, since the oven remains inoperable until they are carried out in laboratory tests that serve as the basis for setting the temper oven.

The research problem is characterized by the absence of statistical models in the writing, that adequately represent the mechanical results in wiredrawn steel wires SAE 9254, tempered in liquid polymer. Steel mills have sought to develop these mathematical models to reduce the amount of laboratory tests and the time to set up the ovens, which can mean reducing costs for the company.

\section{Heat Treatment Process and Mechanical Testing}

Quenching aims to obtain a microstructure that provides high hardness and tensile strength limit. It is related to sudden cooling after heating the steel to austenitizing temperature and aims to obtain a microstructure that provides the mechanical properties for specific applications that require this condition. During the cooling stage in quenching the temperature drop promotes structural changes that result in the emergence of internal tensions and so it is necessary the realization of tempering. The tempering involves a series of micro structural transformations that tend to thermodynamic equilibrium. It is, therefore, a thermally activated process and thus direct function of time and temperature. This process is performed in addition to quenching being particularly important in the manufacture of steel for springs. It consists of heating the quenched material between $250^{\circ} \mathrm{C}$ to $650^{\circ} \mathrm{C}$ for a certain time, to increase the 
ductility and elastic (Callister, 2012).

Test of tensile strength limit the body of proof shall be on the head of testing machine that applies an effort which tends to lengthen it up to the break, being measures the deformation by means of a device called a strain gauge. The test is performed on a body of proof with standardized dimensions, so that the results obtained can be compared, reproduced and measured on the machine itself. Usually the test occurs until the break of the material (what ranks as destructive) and it allows you to measure the resistance of the material and the deformation as a function of applied voltage. This variation is extremely useful for engineering, and it is determined by the route of the stress-strain curve. Above a certain level of tension, the materials begin to deform plastically until the break, at which point you get the limit of tensile strength (Chiaverini, 2012).

Steel industries are very used the universal testing machine of traction and it is common for the units of force used are kilogram-force per square millimeter $(\mathrm{kgf} / \mathrm{mm} 2)$ or MegaPascal (MPa). The technical standards used for the execution of mechanical tests are elaborated by the ASTM (American Society for Testing and Materials).

\section{Methodology}

In the planning of experiments the first step is the choice of the variables (factors) of the process entry that should be investigated. The output variables that will be monitored are then chosen. These input factors may be qualitative or quantitative and the output variables, whenever possible, should be quantitative to provide more accurate statistical analysis (Lima et al., 2011).

Montgomery (2009) proposed the following steps for the development of an industrial design of experiments:

- Characterization of the problem;

- Choice of influence factors and levels;

- Selection of response variables;

- Determination of an experiment planning model;

- Conducting the experiment;

- Data analysis;

- Conclusions and recommendations.

A design of experiments is a test or a series of tests, which purposeful changes are made input variables of a process, so we can observe and identify the corresponding changes in the response variable. The process can be understood as a combination of machines, methods, and people, which transform process entries into a product (process output).

The most appropriate statistical methods for investigating influential variables in processes is the design of experiments (DOE). Design of Experiments can be used in process development and process troubleshooting, to improve your performance or to achieve a robust process (Souza et al., 2011).

A mathematical model consists of a set of equations that represent in a quantitative way the hypotheses that were used in the construction of the model. Such equations are solved according to some values known or predicted by the real world and can be tested through comparation with the known data (Sodré, 2007).

Multiple regression is a sets of statistical techniques used to construct mathematical models that describe the relationships between input variables and output variables of a given process. The difference between simple linear and multiple regression is that in multiple two or more input variables are treated. (Benyounis \& Olabi, 2008).

Montgomery \& Runger (2009) pointed out that multiple regression is used for situations involving more than one regressor and can be expressed as (1).

$$
Y=\beta_{0}+\beta_{1} x_{1}+\beta_{2} x_{2}+\ldots+\beta_{n} x_{n}+\varepsilon
$$

In this expression $Y$ represents the dependent variable, the independent variables are represented by and it is the random error term. The unknown parameters are $\beta_{0}, \beta_{1}, \beta_{2}$ and $\beta_{\mathrm{n}}$. In this model, the $\beta_{0}$ parameter is the intersection of the plane, $\beta_{1}, \beta_{2}$ and $\beta_{\mathrm{n}}$ are the partial regression coefficients.

The models that include interaction effects can be analyzed by the multiple regression method. An interaction between two variables can be represented by a cross term, because if we admit that $x_{3}=x_{1} x_{2}$ and $\beta_{3}=\beta_{12}$, then, the model including the terms of interaction is obtained by (2).

$$
Y=\beta_{0}+\beta_{1} x_{1}+\beta_{2} x_{2}+\beta_{3} x_{3}+\ldots+\varepsilon
$$

The coefficient of multiple determination $\left(\mathrm{R}^{2}\right)$ is a measure of the amount of reduction in the variability of $\mathrm{Y}$, obtained by the use of the Regressors $X_{1}, X_{2} \ldots X_{k}$. The range of variation of this coefficient is zero to one $\left(0 \leq R_{2} \leq 1\right)$. If the 
value of $\mathrm{R}^{2}$ is close to one, it means that the various variables $\mathrm{x}$ measures, are responsible almost entirely for the variability of Y. Otherwise, $\mathrm{R}^{2}$ will display a value close to zero (Montgomery \& Runger, 2009).

The principal components analysis (PCA) was invented in 1901 by Karl Pearson. It is now most commonly used as an exploratory data analysis tool and to make predictive models. PCA can be done by decomposition into autovalues (own values) of a covariance matrix, usually after centralizing (and normalizing or using Z-scores) the data matrix for each attribute. The PCA results are generally discussed in terms of component scores (scores), also called factor scores (the transformed variable values correspond to a particular data point) and the weight by which each normalized variable the original must be multiplied to obtain the component score.

Its main objective is to explain the structure of variance and covariance of a random vector, composed of random p-variables, by constructing linear combinations of the original variables. These linear combinations are called principal components and they are not correlated with each other (Mingoti, 2007). However, in general, the use of this technique we want to obtain "reduction of the number of variables to be evaluated and interpretation of the constructed linear combinations", that is, the information contained in the original P-variables is replaced by the information contained in $\mathrm{K}(\mathrm{K}<\mathrm{P})$ non-correlated core components. Thus, the random vector variability system composed of the original $\mathrm{P}$-variables is approximated by the random vector variability system containing the $\mathrm{K}$ main components. The quality of the approximation depends on the number of components maintained in the system and can be measured by evaluating the proportion of total variance explained by these (Mingoti, 2007).

Principal components analysis is a mathematical procedure that uses an orthogonal transformation (vector orthogonalization) to convert a set of observations of possibly correlated variables into a set of variable values linearly not correlated with major component calls. The number of principal components is always less than or equal to the number of original variables depending on the application area, the PCA is also known as a discrete Karhunen-Loève (KLT) transform, Hotelling transform or orthogonal decomposition itself ( POD).

The variables observed are decomposed in their self-values (variances) and autovectors (standardized coefficients) in equations of linear combinations by the main component analysis (PCA) technique. All observed variables are standardized and included in the equations of the performance scores of the principal components. The standardization of variables is performed by the value of the variable minus the mean of the group of evaluated variables divided by the standard deviation. Standardization is called standard score or Z-score.

The empirical model of the performance index calculation using principal component analysis is given by (3):

$$
\mathrm{Y}_{\mathrm{n}}=\sum \mathrm{A}_{\mathrm{n}} \mathrm{Z}_{\mathrm{n}}
$$

Where:

$\mathrm{Y}_{\mathrm{n}}=$ These are the scores of the main components of the self-values $>1$; is the sum of the normalized autovectors multiplied by the standardized variables;

$\sum=$ Sum

$A_{n}=$ They are the normalized autovectors (coefficients of autovectors of $X_{n}$ ): are the weightings of the variables;

$\mathrm{Z}_{\mathrm{n}}=$ These are the standardized variables $\left[\left(\mathrm{X}-\mathrm{X}_{\mathrm{bar}}\right) / \sigma\right.$ of $\left.\mathrm{X}\right]$; are the less than average variables of variables divided by the standard deviation of the variables]

OPI = General Performance Index is the performance ranking based on the scores of the principal components of the endpoints >1;

OPI $=\sum Y_{n} \chi_{n} / \sum \chi_{n}$ is the sum of the scores of the principal components of the self-values $>1$ multiplied by the self-values of each component, divided by the sum of self-values;

$\chi_{\mathrm{n}}=$ Eigenvalues $>1$ : is the weighting of the General Performance Index.

Obtaining the principal components involves the decomposition of the covariances matrix of the random vector of interest. If any transformation of this random vector is made, the components must be determined using the covariances matrix relative to the transformed vector. A very usual transformation is the standardization of the variables of the vector by the respective means and standard deviations, generating new variables centered in zero and with variances equal to one. In this specific case, the principal components are determined from the covariances matrix of the original standardized variables, which is equivalent to extracting the principal components using the correlation matrix of the original variables (Mingoti, 2007).

Although P components are needed to reproduce the total variability of a system of interest, most of this variability can be represented by a small number of K principal components (Paiva, 2006). 
Montgomery (2004) states that the main objective of the principal components is to find the new set of orthogonal directions that define the maximum variability in the original data, which, hopefully, will lead to a description of the process requiring considerably less variable than the original variables. The information contained in the complete set of $\mathrm{P}$ principal components is exactly equivalent to the information contained in the complete set of all the original process variables.

In general, we will retain sufficient components to explain a reasonable proportion of the total variability of the process, but there are no clear guidelines on how much variability needs to be explained in order to produce an effective procedure of Process monitoring (Montgomery, 2004).

Only the components corresponding to the autovalues (latent roots) of magnitudes greater than one should be considered. Another way to define the number of components is through the percentage of variance explained. In this case, the researcher should judge if the components sufficiently explain the relationship between the original $\mathrm{P}$ variables. Generally, a good degree of explanation is higher than $75 \%$ and the property of the principal components is the independence between them. In this way, they can replace the original variables and eliminate the multicollinearity problem (Johnson; Wichern, 2007).

Being the auto vector $\mathrm{e}_{\mathrm{i}}$ denoted by $\mathrm{e}_{\mathrm{i}}=\left(\mathrm{e}_{\mathrm{i} 1} \text { ei }{ }_{2} \ldots \mathrm{e}_{\mathrm{ip}}\right)^{\prime}$. Consider the random vector $\mathrm{Y}=\mathrm{O}$ ' $\mathrm{X}$, with $\mathrm{O}$ PXP being the orthogonal matrix (Formula 4) of the PXP dimension (Mingoti, 2007), consisting of the normalized vectors of Matrix $\sum$ pxp, such as:

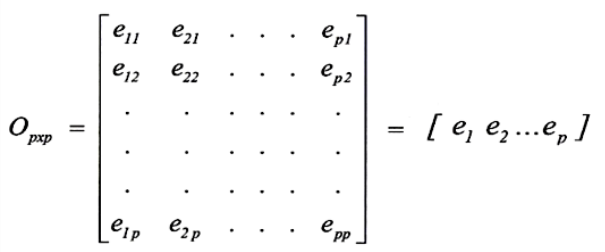

The vector's Y component of $\mathrm{p}$ linear combinations of random variables $\mathrm{X}$, vector has vector of averages equal to the ' $\mu$ and the matrix of covariances pxp, that is a diagonal matrix (Formula 5), whose elements are equal to there $=\mathrm{i}, \mathrm{i}=1.2$, $\mathrm{p}$ this is :

$$
\Lambda_{p \times p}=\left[\begin{array}{ccc}
\lambda_{1} & & \mathbf{0} \\
& \lambda_{2} & \\
\mathbf{o} & & \lambda_{p}
\end{array}\right]
$$

So, as demonstrated by Mingoti (2007), the random variables that constitute the vector Y are not correlated with each other.

Response surface methodology is based on the empirical mathematical models construction usually uses quadratic polynomial functions to offer conditions optimization for systems. The response surface Methodology or RSM is a statistical technique to model processes and optimize the response variables, seeking a maximum or a minimum of income on which to optimize. Typically, using a factorial planning $2^{2}$, investigating two factors, to research the region great, by the way of maximum or minimum rise, depending on what if you want to optimize and the method of least squares is used to estimate the parameters of the quadratic model (polynomial), used to find the best fit of the factors, which will provide achieve the best response variable.

Response surface methodology (or RSM) is an optimization technique based on factorial planning it has been used with great success in the modeling of various types of industrial processes (Neto et al., 2007). Application of response surface methodology is necessary two phases: Modeling and offset. Both should be performed frequently, if necessary, until the ideal surface region investigated is obtained. This modeling is accomplished using linear or quadratic models adjustment, which the responses are obtained through the execution of planning factorials. The offset is made through the path of maximum rise of inclination of a given model, which is the path on which the variable response varies, and it may cause bending, which occurs when a particular answer is increased gradually until at some point, it begins to suffer a fall, this is called point of curvature of the response. Like most issues involving the response surface is unknown, the first procedure is to find an approximation to the true relationship between the response variable (y) and independent variables (factors) and usually uses a mathematical modelling by means of a regression polynomial (quadratic). The following is presented that polynomial regression model of second order is given as (6):

$$
y=\beta_{0}+\sum_{i=1}^{k} \beta_{i} x_{i}+\sum_{i=1}^{k} \beta_{i i} x_{i}^{2}+\sum_{i=1}^{k-1} \sum_{j>i}^{k} \beta_{i j} x_{i} x_{j}+\varepsilon
$$


Being:

- $\beta_{0}$ represents the mean response variable;

- $\sum_{i=1}^{k} \beta_{i} x_{i} \quad$ represents the linear effect;

- $\sum_{i=1}^{k} \beta_{i i} x_{i}^{2}$ represents the quadratic effect;

- $\sum_{i=1}^{k-1} \sum_{j>i}^{k} \beta_{i j} x_{i} x_{j}+\varepsilon \quad$ represents the effect of the interaction.

Statistically analyze the results obtained through experiment planning and response surface methodology (RSM), the most recommended method is the analysis of variance (Anova), whereby, you can compare two or more factors and also test the significance of the regression, using the F-test to establish which factors and interactions between them are really significant in the process as well as testing the significance of the curvature region. From parameters calculated in Anova you can create or validate statistical models, as well as calculate the coefficients necessary for process modeling through multiple regression that can be linear, quadratic or interaction terms (Rosa et al., 2009 \& Correia, 2011).

\section{Material and Factor Selection}

The material used in this study was the SAE 9254 cold drawn steel, used for the manufacture of springs valves and clutch springs applied to the automotive segment, with diameters $2.00 \mathrm{~mm}$ and $6.50 \mathrm{~mm}$, subjected to the process of hardening and tempering. The chemical analysis of the SAE 9254 material used in the study is presented in Table 1.

Table 1. Chemical Composition (SAE 9254)

\begin{tabular}{|c|c|c|c|c|c|c|c|c|c|c|c|}
\hline $\begin{array}{l}\text { Chemical } \\
\text { Elements }\end{array}$ & $\mathrm{C}$ & Mn & $\mathrm{Si}$ & $\mathrm{P}$ & $\mathrm{S}$ & $\mathrm{Cr}$ & $\mathrm{Ni}$ & Mo & $\mathrm{Cu}$ & $\mathrm{Al}$ & V \\
\hline (percentage) & 0.554 & 0.640 & 1.220 & 0.022 & 0.018 & 0.580 & 0.040 & 0.030 & 0.010 & 0.009 & 0.005 \\
\hline
\end{tabular}

The factors chosen for this study were:

- Speed (wire passing inside the oven in $\mathrm{m} / \mathrm{s}$ ) - Factor A;

- Tempering temperature in ${ }^{\circ} \mathrm{C}$ - Factor B.

- Polymer concentration (tempering medium - in \%) -Factor C;

- Diameter in mm - Factor D;

The factors speed, temperature, polymer concentration and diameter were experienced through factorial planning with central point, using matrix $2^{4}$ (with 16 experiments), see Table 2.

Table 2. Experimental $2^{4}$ full Array

\begin{tabular}{ccccc}
\hline Experiments & Speed & Temperature & Polymer & Diameter \\
\hline 1 & - & - & - & - \\
2 & + & - & - & - \\
3 & - & + & - & - \\
4 & + & + & - & - \\
5 & - & - & + & - \\
6 & + & - & + & - \\
7 & - & + & + & - \\
8 & + & + & + & + \\
9 & - & - & - & + \\
10 & + & - & - & + \\
11 & - & + & - & + \\
12 & + & + & + & + \\
13 & - & - & + & + \\
14 & + & - & + & + \\
15 & - & + & + & + \\
16 & + & + & 0 & + \\
\hline
\end{tabular}

You could test the center points (represented by zero (0) in the array for each factor) and also test the minimum and maximum settings.

For planning of experiments, the standardized variables $(\beta)$ were used instead of physical variables (actual adjustments) of the factors investigated, in order to obtain a single dimensional unit for all factors. The reduction of variables was 
calculated using the physical value $(\alpha)$ that is intended to be subsubtracted from the mean $(\mu)$ between the minimum and maximum values of the factors. The result was divided by half the amplitude $(\mathrm{R})$ between the minimum and maximum values of the factors. Thus, the dimensionality of the standardized variables was restricted to the range [-1 to 1], which concentrates the minimum, medium and maximum values, is given by (7):

$$
\beta=\frac{\alpha-\mu}{\frac{R}{2}}
$$

Table 3 shows the relationship between the adjustment levels of physical variables and standardized variables used to calculate the significance test to be performed later.

Table 3. Physical Variables and Standardized Variables

\begin{tabular}{|c|c|c|c|c|}
\hline Factors & \multicolumn{3}{|c|}{ Physical Variables } & Standardized Variables \\
\hline $\begin{array}{l}\text { Speed (rotations per } \\
\text { minute) }\end{array}$ & $\begin{array}{c}\text { Minimum } \\
173\end{array}$ & $\begin{array}{c}\text { Average } \\
189.5\end{array}$ & $\begin{array}{l}\text { Maximum } \\
206\end{array}$ & $-1 / 0 / 1$ \\
\hline Temperature $\left({ }^{\circ} \mathrm{C}\right)$ & $\begin{array}{c}\text { Minimum } \\
435\end{array}$ & $\begin{array}{c}\text { Average } \\
452\end{array}$ & $\begin{array}{c}\text { Maximum } \\
469 \\
\end{array}$ & $-1 / 0 / 1$ \\
\hline Polymer (\%) & $\begin{array}{c}\text { Minimum } \\
15 \\
\end{array}$ & $\begin{array}{c}\text { Average } \\
20.5\end{array}$ & $\begin{array}{l}\text { Maximum } \\
26 \\
\end{array}$ & $-1 / 0 / 1$ \\
\hline Diameter (mm) & $\begin{array}{c}\text { Minimum } \\
2.00\end{array}$ & $\begin{array}{c}\text { Average } \\
4.25\end{array}$ & $\begin{array}{l}\text { Maximum } \\
6.50\end{array}$ & $-1 / 0 / 1$ \\
\hline
\end{tabular}

\section{Results}

First, tempered steel wire samples with a length of 300mm were tested, according to ASTM A370 standard for determination of the tensile strength limit, in an EMIC test machine with a capacity of $60000 \mathrm{kgf}$.

To produce a mathematical model that could be used for diameters from $2.00 \mathrm{~mm}$ to $6.50 \mathrm{~mm}$ it was necessary to use the methods of design of experiments, multiple regression with terms of interaction and significance test (Tstudent). With this, it is expected to estimate the intermediate diameters through a mathematical model. Table 4 will be presented with the experimental conditions of the adjustments of the factors (with four replicates) and the results obtained from the tensile strength limit in MPa.

Table 4. Results of the tensile strength limit

\begin{tabular}{ccccccccc}
\hline Experiments & Speed & Temperature & Polymer & Diameter & \multicolumn{4}{c}{ Tensile strength limit } \\
\hline 1 & - & - & - & - & 2149 & 2148 & 2146 & 2161 \\
2 & + & - & - & - & 2157 & 2155 & 2157 & 2151 \\
3 & - & + & - & - & 1924 & 1922 & 1920 & 1921 \\
4 & + & + & - & - & 1924 & 1924 & 1922 & 1943 \\
5 & - & - & + & - & 2108 & 2106 & 2108 & 2104 \\
6 & + & - & + & - & 2136 & 2127 & 2127 & 2136 \\
7 & - & + & + & - & 1927 & 1926 & 1944 & 1935 \\
8 & + & + & + & - & 1946 & 1946 & 1946 & 1953 \\
9 & - & - & - & + & 1968 & 1974 & 1962 & 1971 \\
10 & + & - & - & + & 1980 & 1976 & 1988 & 1978 \\
11 & - & + & - & + & 1771 & 1764 & 1763 & 1773 \\
12 & + & + & - & + & 1796 & 1784 & 1797 & 1781 \\
13 & - & - & + & + & 1949 & 1963 & 1947 & 1951 \\
14 & + & - & + & + & 1992 & 1980 & 1976 & 1994 \\
15 & - & + & + & + & 1760 & 1768 & 1766 & 1763 \\
16 & + & + & + & + & 1787 & 1793 & 1785 & 1784 \\
Center point & 0 & 0 & 0 & 0 & 2046 & 2040 & 2041 & 2049 \\
\hline
\end{tabular}

Table 5 contains the significance test (Tstudent) of factorial planning, which was calculated using the results contained in Table 4. With this, it is possible to note that all factors were considered influential with $95 \%$ confidence (see Figure 1).

It was also possible to demonstrate that the interactions: Speed * Temperature; Polymer * Diameter; Speed * Temperature * Diameter; Speed * Polymer * Diameter and interaction Speed * Temperature * Polymer * Diameter were not considered influential because they have the P- value $>0.05$ (for $95 \%$ confidence). All other interactions were considered influential with $\mathrm{P}$-value $<0.05$.

It is possible to verify the influence of the factors by analyzing Figure 1 and Table 5, which show that the temperature 
and diameter factors are those that influence the process the most. Similarly, it is possible to observe the behavior of the effects of the factors by analyzing Figure 2. Where adjustment levels increase or decrease the value of the tensile strength limit (see Figure 2). Using the coefficients of the factors and influential interactions, it was possible to build the mathematical model defined by (8).

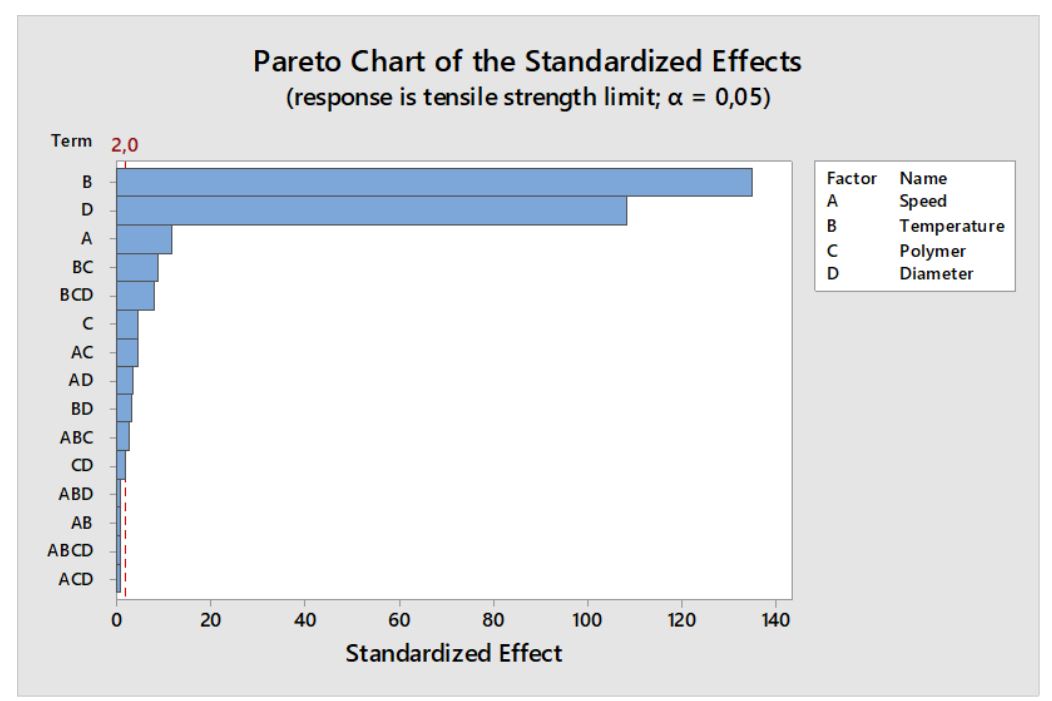

Figure 1. Influence of factors (Pareto diagram of main effects)

Table 5. Factor planning significance test (Tensile strength limit)

\begin{tabular}{|c|c|c|c|c|c|}
\hline Term & Effect & Coef & SE Coef & T-Value & P-Value \\
\hline Constant & & 1954.420 & 0.740 & $2654, .600$ & 0.000 \\
\hline Speed & 17.469 & 8.734 & 0.736 & 11.860 & 0.000 \\
\hline Temperature & -198.969 & -99.484 & 0.736 & -135.120 & 0.000 \\
\hline Polymer & -6.781 & -3.391 & 0.736 & -4.610 & 0.000 \\
\hline Diameter & -159.844 & -79.922 & 0.736 & -108.550 & 0.000 \\
\hline Speed $*$ Temperature & -0.969 & -0.484 & 0.736 & -0.660 & 0.514 \\
\hline Speed*Polymer & 6.469 & 3.234 & 0.736 & 4.390 & 0.000 \\
\hline Speed*Diameter & 4.906 & 2.453 & 0.736 & 3.330 & 0.002 \\
\hline Temperature*Polymer & 13.031 & 6.516 & 0.736 & 8.850 & 0.000 \\
\hline Temperature*Diameter & 4.344 & 2.172 & 0.736 & 2.950 & 0.005 \\
\hline Polymer*Diameter & 2.531 & 1.266 & 0.736 & 1.720 & 0.092 \\
\hline Speed*Temperature*Polymer & -4.094 & -2.047 & 0.736 & -2.780 & 0.008 \\
\hline Speed*Temperature*Diameter & 0.969 & 0.484 & 0.736 & 0.660 & 0.514 \\
\hline Speed*Polymer*Diameter & -0.844 & -0.422 & 0.736 & -0.570 & 0.569 \\
\hline Temperature*Polymer*Diameter & -11.656 & -5.828 & 0.736 & -7.920 & 0.000 \\
\hline $\begin{array}{l}\text { Speed*Temperature*Polymer*Diameter } \\
\text { Curvaturet Point }\end{array}$ & -0.906 & $\begin{array}{l}-0.453 \\
89.580\end{array}$ & $\begin{array}{l}0.736 \\
3.040\end{array}$ & $\begin{array}{l}-0.620 \\
29.510\end{array}$ & $\begin{array}{l}0.541 \\
0.000\end{array}$ \\
\hline $\begin{array}{cc}\mathrm{S} & \mathrm{R}-\mathrm{sq} \\
5.88992 & 99.84 \%\end{array}$ & & & & & \\
\hline
\end{tabular}

Tensile strength limit $=1954.42+8.734$ Speed -99.484 Temperature -3.391 Polymer- 79.922 Diameter +3.234 Speed*Polymer +2.453 Speed*Diameter +6.516 Temperature*Polymer+ 2.172 Temperature*Diameter -2.047 


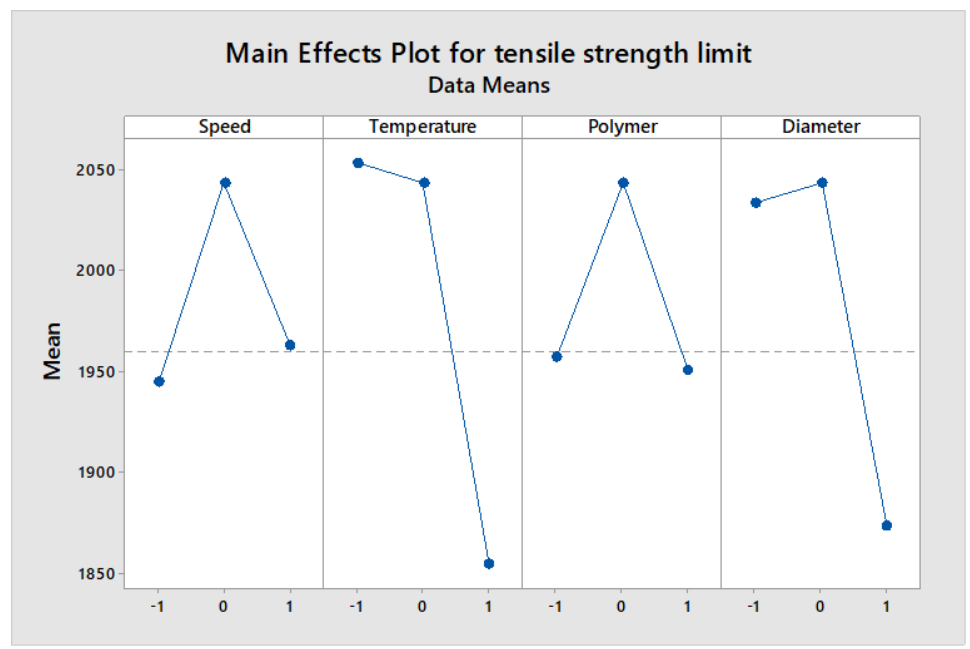

Figure 2. Effects of factors on the response variable (Tensile strength limit)

The residues were generated by the mathematical model using $95 \%$ confidence and demonstrated that there is no normality (with $\mathrm{p}<0.05$ value). This indicates strong evidence that the mathematical model will have difficulties in achieving good results in the predictions of the results (see Figure 3).

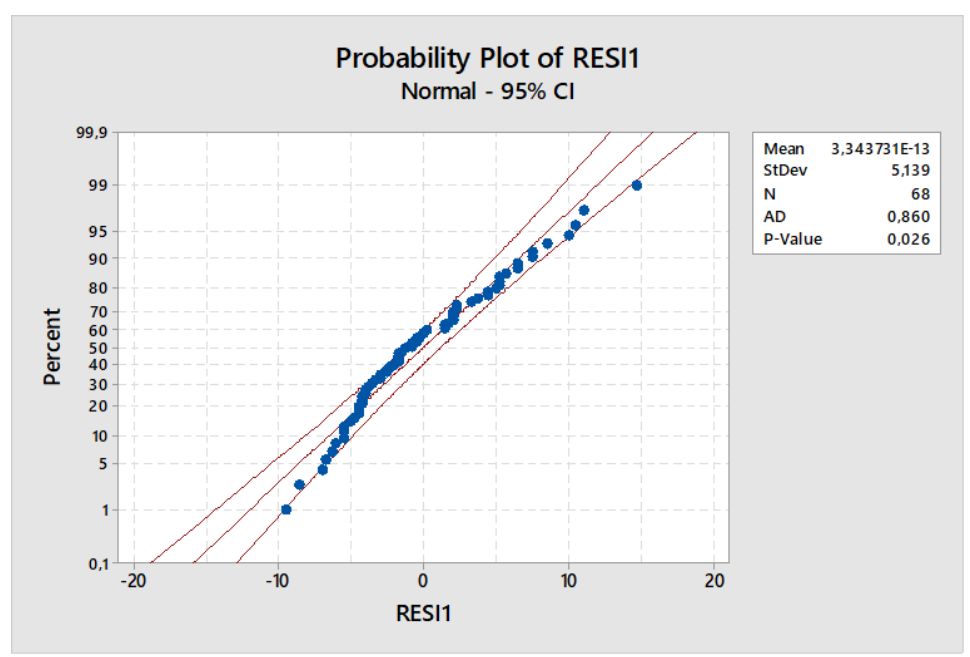

Figure 3. Normality test of residues of the mathematical model

The mathematical model for prediction was created using the coefficient values (see Table 5). However, interactions that were not considered significant were excluded from the mathematical model. The curvature of the process is considered influential $(\mathrm{P}<0.05)$. In this case, there is strong evidence that the linear mathematical model will not obtain good results in the predictions (see Table 5). Therefore, other statistical methods will be tested that will seek alternatives for the construction of new mathematical models so that, at the end of this work, it is possible to choose the mathematical model that best represents this process.

\subsection{Principal Component Analysis}

It is possible to standardize all variables investigated by transforming them into a single dimensional measurement unit (Z). This process is similar to the transformation process applied earlier, but will follow the procedure described in Mingoti (2007). Thus, all factors regardless of your physical unit will have a single measuring unit and will be transformed into principal components.

First, the values of the adjustments of the factors investigated in the design of experiments and their tensile strength limit results were placed in a table (with the exception of the central points). In the last rows of the table 6 , the means and standard deviations of each factor column were calculated. The results are shown below (see Table 6): 
Table 6. Adjustments of factors and experimental results (Tensile strength limit)

\begin{tabular}{|c|c|c|c|c|c|}
\hline $\begin{array}{c}\text { Average and } \\
\text { Standard deviation }\end{array}$ & Speed & Temperature & Polymer & Diameter & $\begin{array}{c}\text { Tensile strength } \\
\text { limit }\end{array}$ \\
\hline & 173 & 435 & 15 & 2.0 & 2149 \\
\hline & 206 & 435 & 15 & 2,0 & 2157 \\
\hline & 173 & 469 & 15 & 2.0 & 1924 \\
\hline & 206 & 469 & 15 & 2.0 & 1924 \\
\hline & 173 & 435 & 26 & 2.0 & 2108 \\
\hline & 206 & 435 & 26 & 2.0 & 2136 \\
\hline & 173 & 469 & 26 & 2,0 & 1927 \\
\hline & 206 & 469 & 26 & 2.0 & 1946 \\
\hline & 173 & 435 & 15 & 6.5 & 1968 \\
\hline & 206 & 435 & 15 & 6.5 & 1980 \\
\hline & 173 & 469 & 15 & 6.5 & 1771 \\
\hline & 206 & 469 & 15 & 6.5 & 1796 \\
\hline & 173 & 435 & 26 & 6.5 & 1949 \\
\hline & 206 & 435 & 26 & 6.5 & 1992 \\
\hline & 173 & 469 & 26 & 6.5 & 1760 \\
\hline & 206 & 469 & 26 & 6.5 & 1787 \\
\hline & 173 & 435 & 15 & 2.0 & 2148 \\
\hline & 206 & 435 & 15 & 2.0 & 2155 \\
\hline & 173 & 469 & 15 & 2.0 & 1922 \\
\hline & 206 & 469 & 15 & 2.0 & 1924 \\
\hline & 173 & 435 & 26 & 2.0 & 2106 \\
\hline & 206 & 435 & 26 & 2.0 & 2127 \\
\hline & 173 & 469 & 26 & 2.0 & 1926 \\
\hline & 206 & 469 & 26 & 2.0 & 1946 \\
\hline & 173 & 435 & 15 & 6.5 & 1974 \\
\hline & 206 & 435 & 15 & 6.5 & 1976 \\
\hline & 173 & 469 & 15 & 6.5 & 1764 \\
\hline & 206 & 469 & 15 & 6.5 & 1784 \\
\hline & 173 & 435 & 26 & 6.5 & 1963 \\
\hline & 206 & 435 & 26 & 6.5 & 1980 \\
\hline & 173 & 469 & 26 & 6.5 & 1768 \\
\hline & 206 & 469 & 26 & 6.5 & 1793 \\
\hline & 173 & 435 & 15 & 2.0 & 2146 \\
\hline & 206 & 435 & 15 & 2.0 & 2157 \\
\hline & 173 & 469 & 15 & 2.0 & 1920 \\
\hline & 206 & 469 & 15 & 2.0 & 1922 \\
\hline & 173 & 435 & 26 & 2.0 & 2108 \\
\hline & 206 & 435 & 26 & 20 & 2127 \\
\hline & 173 & 469 & 26 & 2.0 & 1944 \\
\hline & 206 & 469 & 26 & 2.0 & 1946 \\
\hline & 173 & 435 & 15 & 6.5 & 1962 \\
\hline & 206 & 435 & 15 & 6.5 & 1988 \\
\hline & 173 & 469 & 15 & 6.5 & 1763 \\
\hline & 206 & 469 & 15 & 6.5 & 1797 \\
\hline & 173 & 435 & 26 & 6.5 & 1947 \\
\hline & 206 & 435 & 26 & 6.5 & 1976 \\
\hline & 173 & 469 & 26 & 6.5 & 1766 \\
\hline & 206 & 469 & 26 & 6.5 & 1785 \\
\hline & 173 & 435 & 15 & 2.0 & 2161 \\
\hline & 206 & 435 & 15 & 2.0 & 2151 \\
\hline & 173 & 469 & 15 & 2.0 & 1921 \\
\hline & 206 & 469 & 15 & 2.0 & 1943 \\
\hline & 173 & 435 & 26 & 2.0 & 2104 \\
\hline & 206 & 435 & 26 & 2.0 & 2136 \\
\hline & 173 & 469 & 26 & 2.0 & 1935 \\
\hline & 206 & 469 & 26 & 2.0 & 1953 \\
\hline & 173 & 435 & 15 & 6.5 & 1971 \\
\hline & 206 & 435 & 15 & 6.5 & 1978 \\
\hline & 173 & 469 & 15 & 6.5 & 1773 \\
\hline & 206 & 469 & 15 & 6.5 & 1781 \\
\hline & 173 & 435 & 26 & 6.5 & 1951 \\
\hline & 206 & 435 & 26 & 6.5 & 1994 \\
\hline & 173 & 469 & 26 & 6.5 & 1763 \\
\hline & 206 & 469 & 26 & 6.5 & 1784 \\
\hline Average & 189.50 & 452.00 & 20.50 & 4.25 & \\
\hline Standard deviation & 16.63 & 17.13 & 5.54 & 2.27 & \\
\hline
\end{tabular}

Then, all factor adjustment values were transformed into standardized variables. This transformation was performed by subtracting the value (factor adjustment) from the mean value of this factor. Then, the resulting value was divided by the factor's standard deviation. It is important to inform you that only the factors were submitted to this transformation procedure. For example, (First row of the Table 7): 
Speed standardized $=(173-189.5) / 16.63=-0.992$

Temperature standardized $=(435-452.00) / 17.13=-0.992$

Polymer standardized $=(15-20.50) / 5.54=-0.992$

Diameter standardized $=(2.0-4.25) / 2.27=-0.9921$

All values transformed into a standardized variable are presented (see Table 7):

Table 7. Transformation of factors into standardized variables

\begin{tabular}{|c|c|c|c|}
\hline Speed & Temperature & Polymer & Diameter \\
\hline-0.99215674 & -0.992156742 & -0.992156742 & -0.992156742 \\
\hline 0.99215674 & -0.992156742 & -0.992156742 & -0.992156742 \\
\hline-0.99215674 & 0.992156742 & -0.992156742 & -0.992156742 \\
\hline 0.99215674 & 0.992156742 & -0.992156742 & -0.992156742 \\
\hline-0.99215674 & -0.992156742 & 0.992156742 & -0.992156742 \\
\hline 0.99215674 & -0.992156742 & 0.992156742 & -0.992156742 \\
\hline-0.99215674 & 0.992156742 & 0.992156742 & -0.992156742 \\
\hline 0.99215674 & 0.992156742 & 0.992156742 & -0.992156742 \\
\hline-0.99215674 & -0.992156742 & -0.992156742 & 0.992156742 \\
\hline 0.99215674 & -0.992156742 & -0.992156742 & 0.992156742 \\
\hline-0.99215674 & 0.992156742 & -0.992156742 & 0.992156742 \\
\hline 0.99215674 & 0.992156742 & -0.992156742 & 0.992156742 \\
\hline-0.99215674 & -0.992156742 & 0.992156742 & 0.992156742 \\
\hline 0.99215674 & -0.992156742 & 0.992156742 & 0.992156742 \\
\hline-0.99215674 & 0.992156742 & 0.992156742 & 0.992156742 \\
\hline 0.99215674 & 0.992156742 & 0.992156742 & 0.992156742 \\
\hline-0.99215674 & -0.992156742 & -0.992156742 & -0.992156742 \\
\hline 0.99215674 & -0.992156742 & -0.992156742 & -0.992156742 \\
\hline-0.99215674 & 0.992156742 & -0.992156742 & -0.992156742 \\
\hline 0.99215674 & 0.992156742 & -0.992156742 & -0.992156742 \\
\hline-0.99215674 & -0.992156742 & 0.992156742 & -0.992156742 \\
\hline 0.99215674 & -0.992156742 & 0.992156742 & -0.992156742 \\
\hline-0.99215674 & 0.992156742 & 0.992156742 & -0.992156742 \\
\hline 0.99215674 & 0.992156742 & 0.992156742 & -0.992156742 \\
\hline-0.99215674 & -0.992156742 & -0.992156742 & 0.992156742 \\
\hline 0.99215674 & -0.992156742 & -0.992156742 & 0.992156742 \\
\hline-0.99215674 & 0.992156742 & -0.992156742 & 0.992156742 \\
\hline 0.99215674 & 0.992156742 & -0.992156742 & 0.992156742 \\
\hline-0.99215674 & -0.992156742 & 0.992156742 & 0.992156742 \\
\hline 0.99215674 & -0.992156742 & 0.992156742 & 0.992156742 \\
\hline-0.99215674 & 0.992156742 & 0.992156742 & 0.992156742 \\
\hline 0.99215674 & 0.992156742 & 0.992156742 & 0.992156742 \\
\hline-0.99215674 & -0.992156742 & -0.992156742 & -0.992156742 \\
\hline 0.99215674 & -0.992156742 & -0.992156742 & -0.992156742 \\
\hline-0.99215674 & 0.992156742 & -0.992156742 & -0.992156742 \\
\hline 0.99215674 & 0.992156742 & -0.992156742 & -0.992156742 \\
\hline-0.99215674 & -0.992156742 & 0.992156742 & -0.992156742 \\
\hline 0.99215674 & -0.992156742 & 0.992156742 & -0.992156742 \\
\hline-0.99215674 & 0.992156742 & 0.992156742 & -0.992156742 \\
\hline 0.99215674 & 0.992156742 & 0.992156742 & -0.992156742 \\
\hline-0.99215674 & -0.992156742 & -0.992156742 & 0.992156742 \\
\hline 0.99215674 & -0.992156742 & -0.992156742 & 0.992156742 \\
\hline-0.99215674 & 0.992156742 & -0.992156742 & 0.992156742 \\
\hline 0.99215674 & 0.992156742 & -0.992156742 & 0.992156742 \\
\hline-0.99215674 & -0.992156742 & 0.992156742 & 0.992156742 \\
\hline 0.99215674 & -0.992156742 & 0.992156742 & 0.992156742 \\
\hline-0.99215674 & 0.992156742 & 0.992156742 & 0.992156742 \\
\hline 0.99215674 & 0.992156742 & 0.992156742 & 0.992156742 \\
\hline-0.99215674 & -0.992156742 & -0.992156742 & -0.992156742 \\
\hline 0.99215674 & -0.992156742 & -0.992156742 & -0.992156742 \\
\hline-0.99215674 & 0.992156742 & -0.992156742 & -0.992156742 \\
\hline 0.99215674 & 0.992156742 & -0.992156742 & -0.992156742 \\
\hline-0.99215674 & -0.992156742 & 0.992156742 & -0.992156742 \\
\hline 0.99215674 & -0.992156742 & 0.992156742 & -0.992156742 \\
\hline-0.99215674 & 0.992156742 & 0.992156742 & -0.992156742 \\
\hline 0.99215674 & 0.992156742 & 0.992156742 & -0.992156742 \\
\hline-0.99215674 & -0.992156742 & -0.992156742 & 0.992156742 \\
\hline 0.99215674 & -0.992156742 & -0.992156742 & 0.992156742 \\
\hline-0.99215674 & 0.992156742 & -0.992156742 & 0.992156742 \\
\hline 0.99215674 & 0.992156742 & -0.992156742 & 0.992156742 \\
\hline-0.99215674 & -0.992156742 & 0.992156742 & 0.992156742 \\
\hline 0.99215674 & -0.992156742 & 0.992156742 & 0.992156742 \\
\hline-0.99215674 & 0.992156742 & 0.992156742 & 0.992156742 \\
\hline 0.99215674 & 0.992156742 & 0.992156742 & 0.992156742 \\
\hline
\end{tabular}


After all the transformation of the factors to become standardized variables, the constants that will be used to transform standardized values into key components were calculated. The constants (PCs) correspond to the auto vectors, used for the transformation of the data into principal components (see Table 8).

Table 8. Auto vectors (PCs, Calculated using Minitab Software)

\begin{tabular}{ccrrr}
\hline Variable & $\mathrm{PC}_{1}$ & $\mathrm{PC}_{2}$ & $\mathrm{PC}_{3}$ & $\mathrm{PC}_{4}$ \\
\hline Speed & 0.000 & 0.000 & 0.000 & -1.000 \\
Temperature & 0.000 & 0.000 & -1.000 & 0.000 \\
Polymer & 0.000 & -1.000 & 0.000 & 0.000 \\
Diameter & -1.000 & 0.000 & 0.000 & 0.000 \\
\hline
\end{tabular}

The conversion of the data into principal components should be done by the sum of the multiplication of each value of the factors (speed, temperature, polymer and diameter), by the constants (PCs), referring to each factor.

To apply multiple regression, it was necessary to multiply each of the calculated constants of the PCs (see Table 8) by their respective factors, that is, by the standardized values of the factors investigated in all circumstances experimental. Finally, the components were calculated and will be used later for the creation of the mathematical model. Table 11 shows the values of the calculated constants.

For example, in the first row of Table $11, \mathrm{PC}_{1}$ was multiplied by each standardized factor (speed, temperature, polymer and diameter). Thus, all PCs were calculated for all experimental conditions performed in the design of experiments.

Exemple: The values $-0.99215674 ;-0.992156742 ;-0.99215674 ;-0.992156742$ were removed from the first row of Table 7. The symbols were used to facilitate understanding of how the calculation was performed (see Table 9 , Table 10 and equation 10).

$$
\mathrm{PC}_{1}=\left(\alpha *_{-} 0.99215674\right)+\left(\varphi *_{-} 0.992156742\right)+\left(£_{-}-0.992156742\right)+\left(\omega *_{-} 0.992156742\right)
$$

Table 9. Fragment: Auto vector ( $\mathrm{PC}_{1}$, Calculated using Minitab Software)

\begin{tabular}{ccc}
\hline Variable & $\mathrm{PC}_{1}$ & Symbol \\
\hline Speed & 0.000 & $\alpha$ \\
Temperature & 0.000 & $\varphi$ \\
Polymer & 0.000 & $£$ \\
Diameter & -1.000 & $\omega$
\end{tabular}

Table 10. Fragment: Default factor values [first line (Table 7) for demonstration only]

\begin{tabular}{cccc}
\hline Speed & Temperature & Polymer & Diameter \\
\hline-0.99215674 & -0.992156742 & -0.992156742 & -0.992156742 \\
\hline
\end{tabular}

Table 10 contains the first line of the $\mathrm{PC}_{1}$ calculation, calculated using the information contained in Table 7, Table 9 and using equation (9). All PCs values were presented and also the variable tensile strength limit (see Table 11). Using these values, it was possible to apply the multiple regression method and create the mathematical model using the principal components. 
Table 11. Main components for each experimental condition

\begin{tabular}{|c|c|c|c|c|}
\hline $\mathrm{PC}_{1}$ & $\mathrm{PC}_{2}$ & $\mathrm{PC}_{3}$ & $\mathrm{PC}_{4}$ & $\begin{array}{c}\text { Tensile strength } \\
\text { limit }\end{array}$ \\
\hline 0.992157 & 0.992157 & 0.992157 & 0.992157 & 2149 \\
\hline 0.992157 & 0.992157 & 0.992157 & -0.99216 & 2157 \\
\hline 0.992157 & 0.992157 & -0.99216 & 0.992157 & 1924 \\
\hline 0.992157 & 0.992157 & -0.99216 & -0.99216 & 1924 \\
\hline 0.992157 & -0.99216 & 0.992157 & 0.992157 & 2108 \\
\hline 0.992157 & -0.99216 & 0.992157 & -0.99216 & 2136 \\
\hline 0.992157 & -0.99216 & -0.99216 & 0.992157 & 1927 \\
\hline 0.992157 & -0.99216 & -0.99216 & -0.99216 & 1946 \\
\hline-0.99216 & 0.992157 & 0.992157 & 0.992157 & 1968 \\
\hline-0.99216 & 0.992157 & 0.992157 & -0.99216 & 1980 \\
\hline-0.99216 & 0.992157 & -0.99216 & 0.992157 & 1771 \\
\hline-0.99216 & 0.992157 & -0.99216 & -0.99216 & 1796 \\
\hline-0.99216 & -0.99216 & 0.992157 & 0.992157 & 1949 \\
\hline-0.99216 & -0.99216 & 0.992157 & -0.99216 & 1992 \\
\hline-0.99216 & -0.99216 & -0.99216 & 0.992157 & 1760 \\
\hline-0.99216 & -0.99216 & -0.99216 & -0.99216 & 1787 \\
\hline 0.992157 & 0.992157 & 0.992157 & 0.992157 & 2148 \\
\hline 0.992157 & 0.992157 & 0.992157 & -0.99216 & 2155 \\
\hline 0.992157 & 0.992157 & -0.99216 & 0.992157 & 1922 \\
\hline 0.992157 & 0.992157 & -0.99216 & -0.99216 & 1924 \\
\hline 0.992157 & -0.99216 & 0.992157 & 0.992157 & 2106 \\
\hline 0.992157 & -0.99216 & 0.992157 & -0.99216 & 2127 \\
\hline 0.992157 & -0.99216 & -0.99216 & 0.992157 & 1926 \\
\hline 0.992157 & -0.99216 & -0.99216 & -0.99216 & 1946 \\
\hline-0.99216 & 0.992157 & 0.992157 & 0.992157 & 1974 \\
\hline-0.99216 & 0.992157 & 0.992157 & -0.99216 & 1976 \\
\hline-0.99216 & 0.992157 & -0.99216 & 0.992157 & 1764 \\
\hline-0.99216 & 0.992157 & -0.99216 & -0.99216 & 1784 \\
\hline-0.99216 & -0.99216 & 0.992157 & 0.992157 & 1963 \\
\hline-0.99216 & -0.99216 & 0.992157 & -0.99216 & 1980 \\
\hline-0.99216 & -0.99216 & -0.99216 & 0.992157 & 1768 \\
\hline-0.99216 & -0.99216 & -0.99216 & -0.99216 & 1793 \\
\hline 0.992157 & 0.992157 & 0.992157 & 0.992157 & 2146 \\
\hline 0.992157 & 0.992157 & 0.992157 & -0.99216 & 2157 \\
\hline 0.992157 & 0.992157 & -0.99216 & 0.992157 & 1920 \\
\hline 0.992157 & 0.992157 & -0.99216 & -0.99216 & 1922 \\
\hline 0.992157 & -0.99216 & 0.992157 & 0.992157 & 2108 \\
\hline 0.992157 & -0.99216 & 0.992157 & -0.99216 & 2127 \\
\hline 0.992157 & -0.99216 & -0.99216 & 0.992157 & 1944 \\
\hline 0.992157 & -0.99216 & -0.99216 & -0.99216 & 1946 \\
\hline-0.99216 & 0.992157 & 0.992157 & 0.992157 & 1962 \\
\hline-0.99216 & 0.992157 & 0.992157 & -0.99216 & 1988 \\
\hline-0.99216 & 0.992157 & -0.99216 & 0.992157 & 1763 \\
\hline-0.99216 & 0.992157 & -0.99216 & -0.99216 & 1797 \\
\hline-0.99216 & -0.99216 & 0.992157 & 0.992157 & 1947 \\
\hline-0.99216 & $-0,99216$ & 0.992157 & -0.99216 & 1976 \\
\hline-0.99216 & -0.99216 & -0.99216 & 0.992157 & 1766 \\
\hline-0.99216 & $-0,99216$ & -0.99216 & -0.99216 & 1785 \\
\hline 0.992157 & 0.992157 & 0.992157 & 0.992157 & 2161 \\
\hline 0.992157 & 0.992157 & 0.992157 & -0.99216 & 2151 \\
\hline 0.992157 & 0.992157 & -0.99216 & 0.992157 & 1921 \\
\hline 0.992157 & 0.992157 & -0.99216 & -0.99216 & 1943 \\
\hline 0.992157 & -0.99216 & 0.992157 & 0.992157 & 2104 \\
\hline 0.992157 & -0.99216 & 0.992157 & -0.99216 & 2136 \\
\hline 0.992157 & -0.99216 & -0.99216 & 0.992157 & 1935 \\
\hline 0.992157 & -0.99216 & -0.99216 & -0.99216 & 1953 \\
\hline-0.99216 & 0.992157 & 0.992157 & 0.992157 & 1971 \\
\hline-0.99216 & 0.992157 & 0.992157 & -0.99216 & 1978 \\
\hline-0.99216 & 0.992157 & -0.99216 & 0.992157 & 1773 \\
\hline-0.99216 & 0.992157 & -0.99216 & -0.99216 & 1781 \\
\hline-0.99216 & -0.99216 & 0.992157 & 0.992157 & 1951 \\
\hline-0.99216 & -0.99216 & 0.992157 & -0.99216 & 1994 \\
\hline-0.99216 & -0.99216 & -0.99216 & 0.992157 & 1763 \\
\hline-0.99216 & -0.99216 & -0.99216 & -0.99216 & 1784 \\
\hline
\end{tabular}


The following will be the information containing the statistics related to the principal components. These statistics can be used to select the components to be used in the mathematical model (see Table 12). The explanation of the criteria for the choice of variables will be detailed later.

Table 12. Main components for each experimental condition

\begin{tabular}{crrrr}
\hline Variable & \multicolumn{1}{c}{$\mathrm{PC}_{1}$} & $\mathrm{PC}_{2}$ & \multicolumn{1}{c}{$\mathrm{PC}_{3}$} & $\mathrm{PC}_{4}$ \\
\hline Eigenvalue & 1.0000 & 1.0000 & 1.0000 & 1.0000 \\
Proportion & 0.250 & 0.250 & 0.250 & 0.250 \\
Cumulative & 0.250 & 0.500 & 0.750 & 1.000
\end{tabular}

The autovalues are used to choose the principal components for mathematical modelling (see Table 12), because only the components corresponding to the values of magnitudes equal to or greater than 1 are chosen (Johnson \& Wichern, 2007). In this case, all components will be used in the construction of the model, because the objective is only to achieve a model that can perform predictions efficiently and that meet the required statistical requirements, especially in relation to the normality of the Waste.

When there is intention to reduce the amount of components, it is admitted to use components that accumulate from $70 \%$ to $80 \%$ of the explanation of the phenomenon. The writing states that with an accumulated within this range it is possible to represent the process well and reduce the number of variables.

The content " proportion " defines what is the percentage of influence of each principal component in the response variable. While the cumulative (shows cumulatively) the contribution of the first $\mathrm{PC}$, progressing to the last $\mathrm{PC}$. In this case, $\mathrm{PC}_{1}$ explains $25 \%$ of this phenomenon, $\mathrm{PC}_{1}+\mathrm{PC}_{2}$ explain $50 \%, \mathrm{PC}_{1}+\mathrm{PC}_{2}+\mathrm{PC}_{3}$ explain $75 \%$, while $\mathrm{PC}_{1}+\mathrm{PC}_{2}+$ $\mathrm{PC}_{3}+\mathrm{PC}_{4}$ explain $100 \%$. The "Cumulative " index (see Table 12) refers to the cumulative sum of the percentages of "explanation" of the phenomenon.

A significance test was performed to verify that the principal components and response variable have a significant relationship and the results revealed that all components are significant (see Table 13). Then, the mathematical model was created using the principal components and the model was defined by (11).

Table 13. Significance test for PCs (Tensile strength limit)

\begin{tabular}{lrcrc}
\hline Term & Coef & SE Coef & T-Value & P-Value \\
\hline Constant & 1954.42 & 1.49 & 1311.32 & 0.000 \\
$\mathrm{PC}_{1}$ & 80.55 & 1.50 & 53.62 & 0.000 \\
$\mathrm{PC}_{2}$ & 3.42 & 1.50 & 2.27 & 0.027 \\
$\mathrm{PC}_{3}$ & 100.27 & 1.50 & 66.75 & 0.000 \\
$\mathrm{PC}_{4}$ & -8.80 & 1.50 & -5.86 & 0.000 \\
$\mathrm{~S}$ & $\mathrm{R}-\mathrm{sq}$ & $\mathrm{R}$-sq(adj) & & \\
11.9234 & $99.21 \%$ & $99.15 \%$ & & \\
\hline
\end{tabular}

The mathematical model using the principal components was created:

$$
\text { Tensile strength limit }=1954.42+80.55 \mathrm{PC}_{1}+3.42 \mathrm{PC}_{2}+100.27 \mathrm{PC}_{3}-8.80 \mathrm{PC}_{4}
$$

The analysis of the normality of the residues found that the residues follow the distribution of normal probability, which is fundamental for the use of a mathematical model to make good predictions. It is shown to the residual normality chart with $\mathrm{P}>$ value 0.05 to $95 \%$ confidence (see Figure 4 ). 


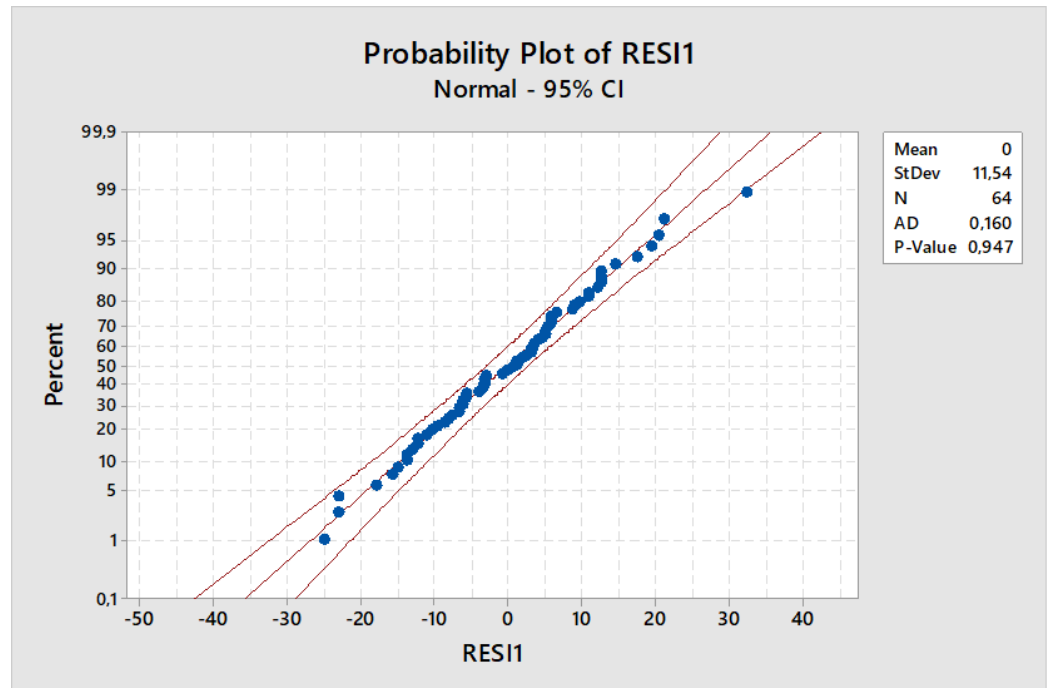

Figure 4. Normality test of residues of the mathematical model (Model by Principal Component Analysis)

However, it was observed at the beginning of the first phase of experimentation using the results of experiment planning (DOE), that there is evidence that the process has a curvature point. There is evidence that it is necessary in addition to the creation of a model linear mathematician, also the creation of a quadratic model. Taking into account the curvature of the process, the same procedure (previously performed for the transformation of factors into main components) was performed to create a quadratic model using the main components. Then, the values of the central points obtained in the previous phase were added (see Table 14).

Table 14. Curvature points values obtained in the previous experiment design (Tensile strength limit)

\begin{tabular}{ccccc}
\hline Speed & Temperature & Polymer & Diameter & Tensile strength limit \\
\hline 189.5 & 452 & 20.5 & 425 & 2046 \\
189.5 & 452 & 20.5 & 425 & 2040 \\
189.5 & 452 & 20.5 & 425 & 2041 \\
189.5 & 452 & 20.5 & 425 & 2049 \\
\hline
\end{tabular}

A new multiple regression was performed and a new significance test was generated (see Table 15):

Table 15. Significance test for PCs (Tensile strength limit)

\begin{tabular}{lcccc}
\hline Term & \multicolumn{1}{c}{ Coef } & SE Coef & T-Value & P-Value \\
\hline Constant & 1959.69 & 9.92 & 197.46 & 0.000 \\
$\mathrm{PC}_{1}$ & -0.443 & 0.227 & -1.95 & 0.056 \\
$\mathrm{PC}_{2}$ & 3.4 & 10.3 & 0.33 & 0.741 \\
$\mathrm{PC}_{3}$ & 100.3 & 10.3 & 9.72 & 0.000 \\
$\mathrm{PC}_{4}$ & -8.8 & 10.3 & -0.85 & 0.396 \\
$\mathrm{~S}$ & $\mathrm{R}-\mathrm{sq}$ & $\mathrm{R}$-sq(adj) & & \\
81.8396 & $61.16 \%$ & $58.70 \%$ & &
\end{tabular}

After analysing the significance test, it was possible to prove that with the addition of the factors tested at the central point, the mathematical model using principal components became non-significant, obtaining the value of the coefficient of low determination and high standard deviation. In this case, it makes no sense that only the $\mathrm{PC}_{3}$ component is significant. To prove the impossibility of using the quadratic mathematical model, the residues of this model were also analyzed and the analysis proved that the residues do not follow the normal distribution, which is necessary for the proper functioning of a mathematical model with $\mathrm{P}<0.05$, for $95 \%$ confidence (see Figure 5): 


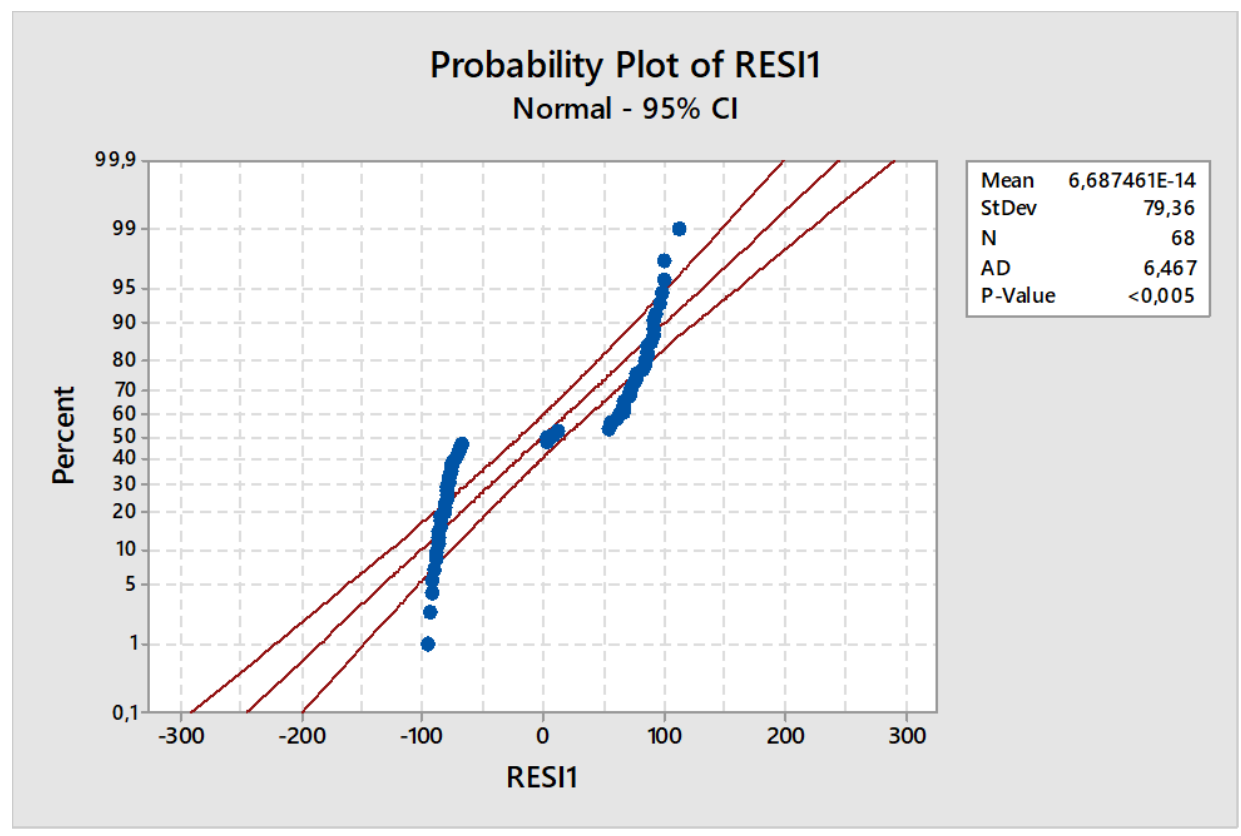

Figure 5. Normality test of residues. Model by Principal Component Analysis, using center points (curvature points)

Through these preliminary studies, investigating only the effect of factors on the variable traction resistance limit response, it was possible to acquire important information about the behavior of this process. However, it was observed that for an application in "Shop floor" this model consisting of the analysis of main components became very complex, due to all the mathematical transformation necessary. In addition, more tests are needed to try to create a quadratic mathematical model that can represent the curvature point of the process, which has so far not been possible. However, the next phase of this work will demonstrate the use of the response surface methodology for the creation of the quadratic model that will try to better represent the process and obtain good predictions.

\subsection{Application of Response Surface Methodology}

There is evidence that when the velocity value (factor A) increases and decreases temperature (factor B), the tensile strength limit will be increased. However, the evidence points out that in a given setting this mechanical property will reach its peak and then it will begin to decline, then causing curvature.

For the creation of a mathematical modeling process using the response surface methodology it was necessary to study the diameters separately, creating a quadratic function for the diameter of $2.00 \mathrm{~mm}$ and another quadratic function for the diameter of $6.50 \mathrm{~mm}$. In this way, you can obtain the specific models for each diameter.

\subsection{Response Surface Methodology (diameter 2.00mm)}

First, the experiments were carried out only for the diameter of $2.00 \mathrm{~mm}$, making a sequence of experiments in the region in which the curvature of the process can be found. In this stage, only the two main factors (A and B) were studied. Together, they explain almost all influence generated in the variable traction resistance limit response (two replicas were used for each experimental condition). The experimental sequence and the results obtained after the experiments are presented (see Table 16). 
Table 16. Experimental matrix for quadratic modeling of the tensile strength limit $2.00 \mathrm{~mm}$ (MPa)

\begin{tabular}{ccc}
\hline Speed & Temperature & Tensile strength limit \\
\hline-1 & -1 & 2149 \\
1 & -1 & 2157 \\
-1 & 1 & 1924 \\
1 & 1 & 1924 \\
-1.41 & 0 & 2014 \\
1.41 & 0 & 2050 \\
0 & -1.41 & 2075 \\
0 & 1.41 & 1880 \\
0 & 0 & 2046 \\
0 & 0 & 2040 \\
0 & 0 & 2041 \\
0 & 0 & 2049 \\
0 & 0 & 2042 \\
-1 & -1 & 2148 \\
1 & -1 & 2155 \\
-1 & 1 & 1922 \\
1 & 1 & 1924 \\
-1.41 & 0 & 2010 \\
1.41 & 0 & 2062 \\
0 & -1.41 & 2090 \\
0 & 1.41 & 1885 \\
0 & 0 & 2045 \\
0 & 0 & 2042 \\
0 & 0 & 2048 \\
0 & 0 & 2049 \\
0 & 0 & 2040 \\
\hline
\end{tabular}

After completing the experiments, a new significance test was performed for the diameter of $2.00 \mathrm{~mm}$ (using the Tstudent statistic). Through this test (see Table 17), it was found that the velocity factor (A) was not considered influential, as well as its quadratic term. While the temperature factor (B) and its quadratic term were considered influential. However, in quadratic modeling, it was observed that the interaction term was not considered influential in the tested conditions.

Table 17. Significance test for quadratic modeling (tensile strength limit $-\varnothing 2.00 \mathrm{~mm}$ )

\begin{tabular}{lccccc}
\hline Term & Effect & \multicolumn{1}{c}{ Coef } & SE Coef & T-Value & P-Value \\
\hline Constant & & 2044.20 & 7.81 & 261.87 & 0.000 \\
Speed & 17.68 & 8.84 & 6.17 & 1.43 & 0.167 \\
Temperature & -185.09 & -92.54 & 6.17 & -15.00 & 0.000 \\
Speed*Speed & 4.61 & 2.31 & 6.62 & 0.35 & 0.731 \\
Temperature*Temperature -46.89 & -23.44 & 6.62 & -3.54 & 0.002 \\
Speed*Temperature & -3.25 & -1.62 & 8.73 & -0.19 & 0.854 \\
S & R-sq & R-sq(adj) & & & \\
24.6856 & $92.31 \%$ & $90.39 \%$ & & & \\
\hline
\end{tabular}

To better understand the response surface of the tensile resistance limit $(\varnothing 2.00 \mathrm{~mm})$, a three-dimensional graph was constructed (see Figure 6). It shows the behavior of the response variable in relation to the adjustments of the factors. Analyzing the data, it is possible to observe that reducing the temperature factor adjustment (B) from Level 1 to -1 causes an increase in the tensile strength limit (see figure 6). It is possible to explain this phenomenon, because with the reduction of the temperature of the liquid polymer (tempering medium), the steel wire heated inside the oven, will have a greater thermal shock when coming into contact with the polymer and this will result in a more severe temper, which will cause increase in the tensile strength limit. 


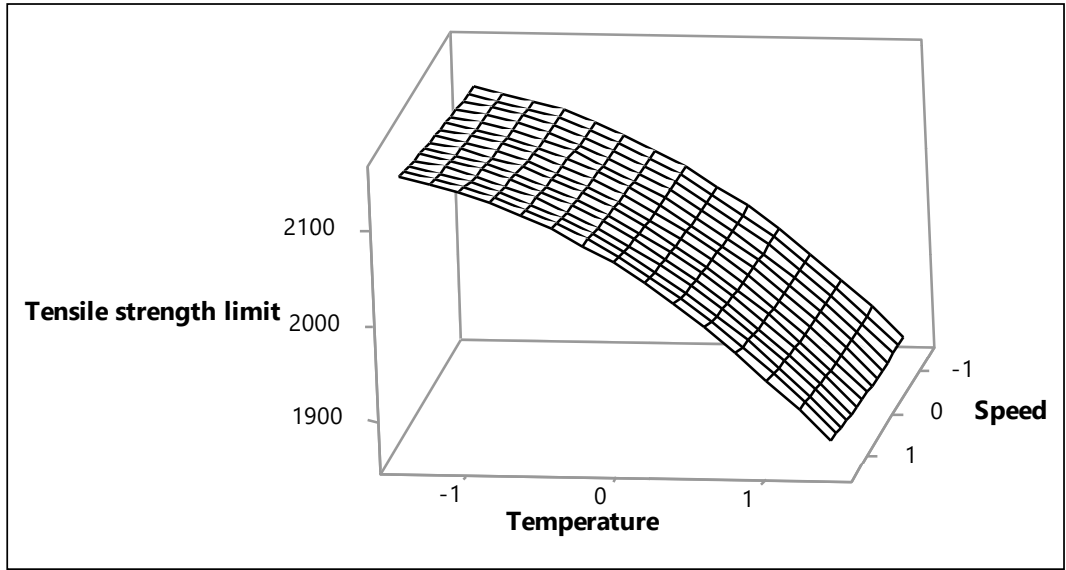

Figure 6. Tensile strength limit response surface - $\varnothing 2.00 \mathrm{~mm}$ (MPa)

The residues generated for the mathematical model $(\varnothing 2.00 \mathrm{~mm})$ using the response surface methodology showed normal probability distribution ( $\mathrm{P}>0.05$ ) using $95 \%$ confidence. The results of the residue analysis are presented (see Figure 7):

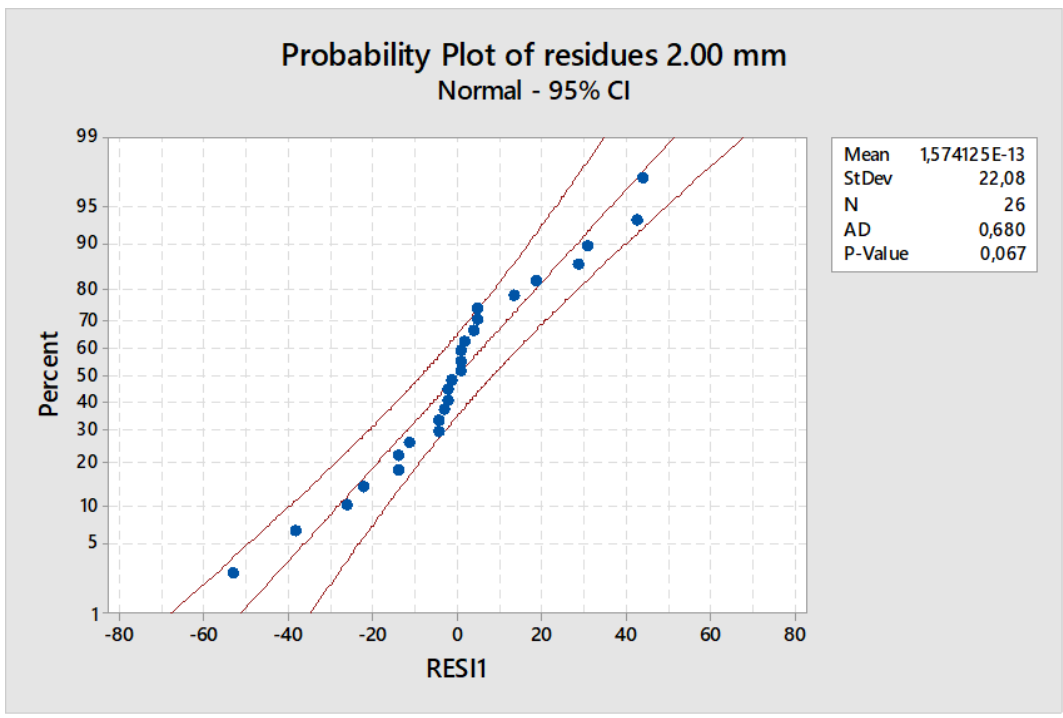

Figure 7. Normality test of residues-Tensile strength limit response surface - $\varnothing 2.00 \mathrm{~mm}(\mathrm{MPa})$

\subsection{Response Surface Methodology (Diameter 6.50mm)}

Analysing the response surface for the diameter of $6.50 \mathrm{~mm}$, two main factors (A and B) were studied. Together, they explain almost all the influence generated in the response. They are presented the experimental sequence and the results obtained after the design of experiments (see Table 18). 
Table 18. Quadratic model experimental matrix of the tensile strength limit- $\varnothing 6.50 \mathrm{~mm}(\mathrm{MPa})$

\begin{tabular}{|c|c|c|}
\hline Speed & Temperature & Tensile strength limit \\
\hline-1 & -1 & 1968 \\
\hline 1 & -1 & 1980 \\
\hline-1 & 1 & 1771 \\
\hline 1 & 1 & 1796 \\
\hline-1.414213562 & 0 & 1800 \\
\hline 1.414213562 & 0 & 1820 \\
\hline 0 & -1.414213562 & 2060 \\
\hline 0 & 1.414213562 & 1750 \\
\hline 0 & 0 & 2046 \\
\hline 0 & 0 & 2040 \\
\hline 0 & 0 & 2041 \\
\hline 0 & 0 & 2049 \\
\hline 0 & 0 & 2042 \\
\hline-1 & -1 & 1974 \\
\hline 1 & -1 & 1978 \\
\hline-1 & 1 & 1764 \\
\hline 1 & 1 & 1784 \\
\hline-1.414213562 & 0 & 1805 \\
\hline 1.414213562 & 0 & 1835 \\
\hline 0 & -1.414213562 & 2070 \\
\hline 0 & 1.414213562 & 1758 \\
\hline 0 & 0 & 2045 \\
\hline 0 & 0 & 2042 \\
\hline 0 & 0 & 2048 \\
\hline 0 & 0 & 2049 \\
\hline 0 & 0 & 2040 \\
\hline
\end{tabular}

After performing the experiments in order to know the significance of the factors and mathematically model the process, the significance test was performed (see Table 19), which allowed the perception that the factors velocity (A) and temperature (B) are influential for the diameter $6.50 \mathrm{~mm}$, as well as the quadratic terms of $\mathrm{A}$ and $\mathrm{B}$, with $\mathrm{P}$ values lower than $5 \%(\mathrm{P}<0.05)$. However, for quadratic modeling, it was observed that the interaction was not influential.

Table 19. Significance test of the quadratic model of the tensile strength limit- $\varnothing 6.50 \mathrm{~mm}(\mathrm{MPa})$

\begin{tabular}{|c|c|c|c|c|c|}
\hline Term & Effect & Coef & SE Coef & T-Value & P-Value \\
\hline Constant & & 2044.20 & 3.05 & 669.54 & 0.000 \\
\hline Speed & 16.46 & 8.23 & 2.41 & 3.41 & 0.003 \\
\hline Temperature & -208.08 & -104.04 & 2.41 & -43.10 & 0.000 \\
\hline Speed*Sp & -221.89 & -110.94 & 2.59 & -42.86 & 0.000 \\
\hline Temperature*Temperature & -127.39 & -63.69 & 2.59 & -24.61 & 0.000 \\
\hline Speed*Temperature & 7.25 & 3.63 & 3.41 & 1.06 & 0.301 \\
\hline R-sq & & $(\operatorname{adj})$ & & & \\
\hline 9.65495 & & $39 \%$ & & & \\
\hline
\end{tabular}


For a better understanding of the response surface of the diameter of $6.50 \mathrm{~mm}$, a three-dimensional graph was constructed (see Figure 8), showing the behavior of the tensile strength limit in relation to the adjustments of the factors.

Analyzing the date, it is possible to prove that the speed is responsible for the degree of intensity of thermal shock at the time of tempering, as steel wire after passing through the heating phases inside the oven will come into contact with the polymer, cooling faster, depending on the increase in the speed (see Figure 8). So if a high processing speed is used there will be no time for heat dissipation of the steel wire into the atmosphere, thereby extending the intensity of thermal shock when the steel wire comes into contact with the polymer at the time of cooling and this will cause the tensile strength limit to increase. However, excessive increase in processing speed (A) above the curvature point will cause the wire to pass so quickly through the temper that there will not be enough time for the (crude) micro structure of the material to undergo the necessary transformation to become a seasoned wire.

It is also possible to observe (see Figure 8), that reducing the temperature (B) from level 1 to -1 causes an increase in the tensile strength limit. It is possible to explain this phenomenon, because with the reduction of the temperature of the liquid polymer (tempering medium), the steel wire heated inside the oven, will have a greater thermal shock when coming into contact with the polymer and this will result in a more severe temper, which will cause increase in the tensile strength limit.

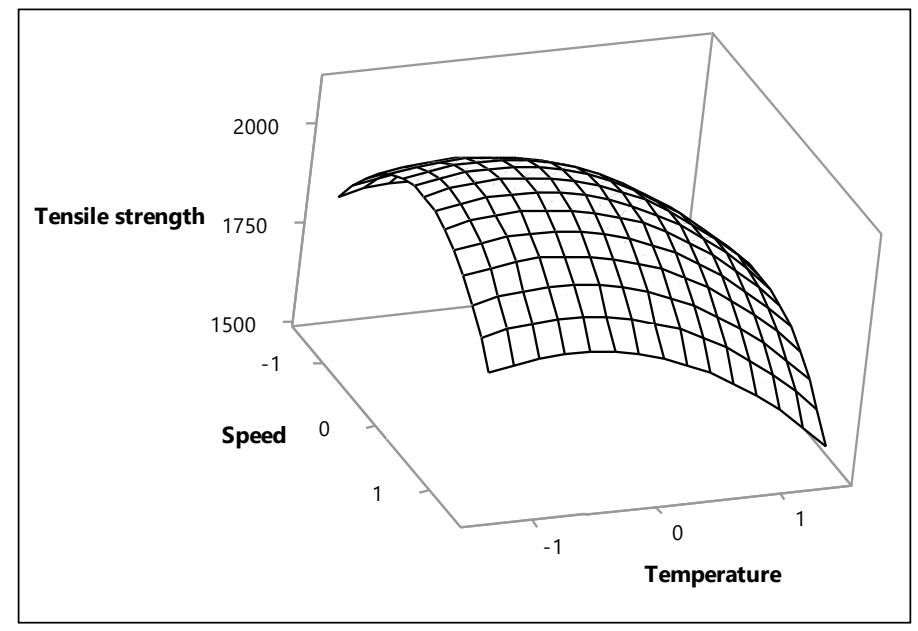

Figure 8. Tensile strength Limit Response surface - $\varnothing 6.50 \mathrm{~mm}(\mathrm{MPa})$

The residues generated for the mathematical model $(\varnothing 6.50 \mathrm{~mm})$ using the response surface methodology showed normal probability distribution $(\mathrm{P}>0.05)$ to $95 \%$ confidence. The results of the residue analysis are presented below (see Figure 9):

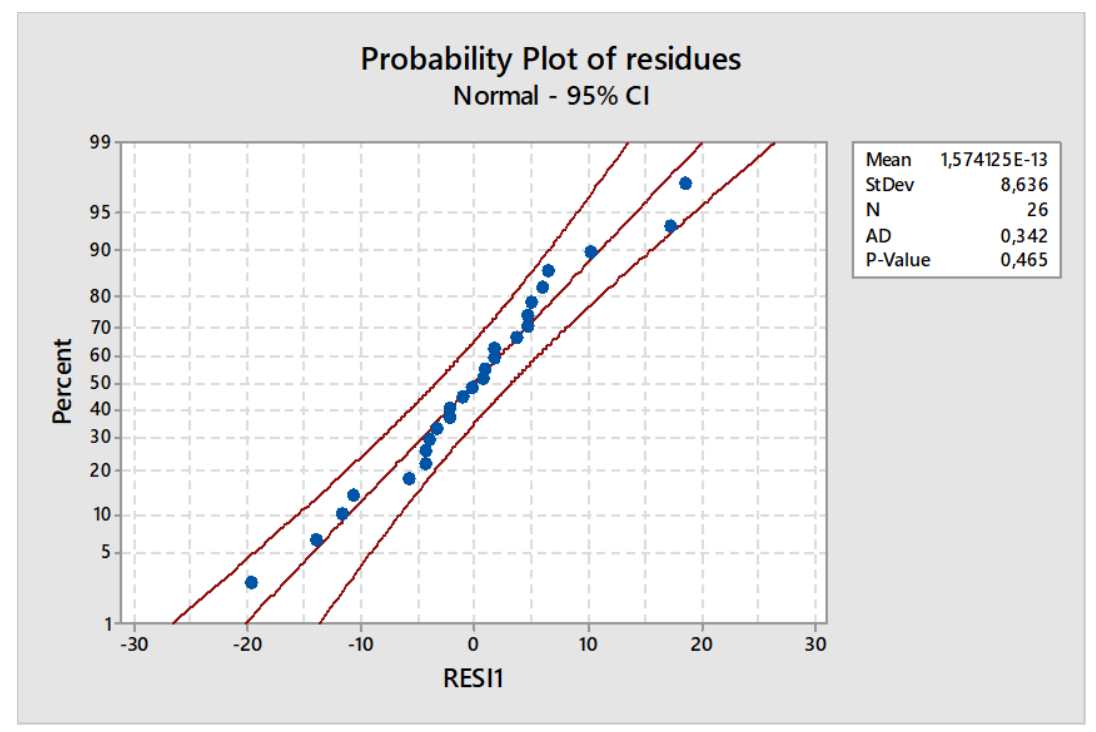

Figure 9. Normality test of residues-Tensile strength limit response surface - $\varnothing 6.50 \mathrm{~mm}(\mathrm{MPa})$ 
Using the information contained in Tables 17 and 19, the quadratic mathematical models of the tempering process were created for diameters $2.00 \mathrm{~mm}$ and $6.50 \mathrm{~mm}$. Regarding the diameter $2.00 \mathrm{~mm}$, the velocity factor and its interaction were removed from the model, as they were not considered influential. Using the coefficients for the diameter of 2.00 $\mathrm{mm}$ (see Table 17), the following quadratic equation was created (12):

Tensile strength limit $=2044.20-92.54$ Temperature -23.44 Temperature*Temperature

In relation to diameter $6.50 \mathrm{~mm}$, using the coefficients (Table 19), the following quadratic equation was created (13):

Tensile strength limit $=2044.20+8.23$ Speed -104.04 Temperature -110.94 Speed*Speed

$$
\text { - 63.69 Temperature*Temperature }
$$

\section{Conclusions}

It was concluded through the planning of experiments (without the inclusion of central points) that all factors (speed, temperature, polymer concentration and diameter) are influential in the process of tempering in steel wires SAE 9254 and that these factors interact with each other, significantly. However, the temperature factor is the most important and it has the greatest impact on increasing or reducing the tensile strength limit.

It was also verified that the modeling containing all diameters between $2.00 \mathrm{~mm}$ and $6.50 \mathrm{~mm}$ did not achieve a great result, due to the lack of normality of the residues of the mathematical model and also due to the existence of the curvature point in the process.

It was possible to verify that modeling using the methodology of principal component analysis obtained good results, but it became very complex for the use of the mathematical model in the productive area and this model was considered unfeasible from the point of view operating. Statistically, this model was disapproved in the analysis of the residues, showing that they are not normal, when the central points are included.

It was observed that the best form of mathematical modeling for this process was through the response surface methodology, because this methodology provided a model that can explain the curvature of the process and the residues generated by the mathematical model follow the distribution of normal probability, which contributed to the validation of this model.

It was concluded with this study that the statistical methods studied in academic environments apply perfectly in an industrial environment, solving complex problems and being of great value for future industrial innovations. However, planning for these experiments in the industrial environment requires a lot of attention and care in choosing the appropriate methods to be used. In an industrial environment, with a large scale of production, an error in experimentation can mean large financial losses. However, the success of the experiments may bring great technological advances that may result in productivity and quality gain for the company.

\section{References}

Benyounis, K. Y., \& Olabi, A. G. (2008). Optimization of different welding processes using statistical and numerical approaches - A reference guide. Advances in Engineering Software, 39(6), 483-496. https://doi.org/10.1016/j.advengsoft.2007.03.012

Callister, W. D., \& Rethwisch, D. G. (2012). Ciência e engenharia de materiais: uma introdução (8th ed.). LTC, 700-724.

Chiaverini, V. (2012). Aços e ferros fundidos (7th ed.). São Paulo: Associação brasileira de metalurgia e materiais, 550-600.

Correia, E. A. S., \& Cardoza, J. A. S. (2011). Planejamento de experimentos no processo produtivo utilizando o método Taguchi. Gestão da produção operações e sistemas, 6(1), 55-66, 1984-2430.

Johnson, R. A., \& Wichern, D. W. (2007). Applied multivariate statistical analysis (6th ed.). New jersey: Prentice hall, 490- 500.

Lima, V. B. S., Balestrassi, P. P., \& Paiva, A. P. (2011). Otimização do desempenho de amplificadores de radio frequência banda larga: uma abordagem experimental. Produção, São Paulo, 21(1), 118-131. https://doi.org/10.1590/S0103-65132011005000005

Mingoti, S. A. (2007). Análise de dados através de métodos de estatística multivariada, uma abordagem aplicada (1st ed.). Belo Horizonte, 290-295.

Montgomery, C. D. (2004). Introdução ao controle estatístico da qualidade (4th ed.). New York: LTC, 510-513.

Montgomery, D. C., \& Runger, G. C. (2009). Estatística aplicada e probabilidade para engenheiros (4th ed.). New York: LTC, 500-514. 
Neto, B. B., Scarminio, I. S., \& Bruns, R. E. (2007). Como fazer experimentos: pesquisa e desenvolvimento na ciência e na indústria (3nd ed.). Campinas: Unicamp, 470-480.

Paiva, E. J. (2006). Otimização de manufatura com múltiplas respostas baseadas em índices de capacidade. Itajubá, 110-117.

Robin; A., Rosa, J. L., \& Silva, M. B. (2010). Electrodeposition and characterization of cu-nb composite coatings. Surface \& coatings technology, 205(1), 2152-2159. https://doi.org/10.1016/j.surfcoat.2010.08.124

Rosa, J. L., Robin, A., Silva, M. B., Baldan, C. A., \& Peres, M. P. (2009). Electrodeposition of copper on titanium wires: taguchi experimental design approach. Journal of materials processing technology, 209(1), 1181-1188. https://doi.org/10.1016/j.jmatprotec.2008.03.021

Silva, K. G. (2013). Uso de simulated annealing e algoritmo genético no problema da reconfiguração de uma rede de distribuição de energia elétrica. Natal, 20-30.

Sodré, M. (2007). Sobre a episteme comunicacional. Matrizes USP, São Paulo, 1(1), 15-26. https://doi.org/10.11606/issn.1982-8160.v1i1p15-26

Souza, H. J. C., Moyses, C. B., Pontes, F. J., Duarte, R. N., Silva, C. E. S., Alberto, F. L., ... Silva, M. B. (2011). Optimization molecular assay optimized by taguchi experimental design method for venous thromboembolism investigation. Molecular and cellular probes, Sidney, 25(1), 231-237. https://doi.org/10.1016/j.mcp.2011.08.001

\section{Copyrights}

Copyright for this article is retained by the author(s), with first publication rights granted to the journal.

This is an open-access article distributed under the terms and conditions of the Creative Commons Attribution license (http://creativecommons.org/licenses/by/4.0/). 